\title{
The Influence of Instruction Behavior in University Ski Class on Students' Learning Attitude, Sport Commitment, and Intention for Physical Activity Adherence in China
}

\author{
Tan Rui ${ }^{1}$,Hyunchoul $\mathrm{Cho}^{2}$, Jaepil Seo ${ }^{3}$, Choi Chul Yung ${ }^{4}$, Yansen $\mathrm{Li}^{5 *}$ \\ ${ }^{1}$ Institute of Winter Olympic, Harbin Sport University, Harbin150008, Heilongjiang, \\ China \\ 2,3,5* Department of Physical Education, Woosuk Univ., 443 Samnye-ro, Samnye-eup, \\ Wanju-gun, Jeollabuk-do, 55338 Republic of Korea \\ ${ }^{4}$ Dept. of leisure sports, Cheju Halla Univ.,38 Halladaehak-ro, Jeju-si, Jeju Special \\ Self-Governing Province, 63092, Republic of Korea \\ Itanrui8602@hotmail.com, ${ }^{2}$ chojudo@daum.net, ${ }^{3}$ sjp0330@naver.com, ${ }^{4}$ ccy@chu.ac.kr, \\ 5*513088839@qq.com
}

\begin{abstract}
The aim of this study is to investigate on the influence of the instruction behavior in Chinese university ski classes on students' learning attitude, sport commitment, and intention for physical activity adherence. A total of 482 responses were gathered through a survey from college students who participated in the ski class at H Sports University which opened alpine skiing selective courses in China. The collected data go through regression analysis using the SPSS 22.0 statistical software. The research indicates that the instruction behavior of the Chinese university ski class has a positive influence on learning attitude. The instruction behavior has a positive influence on sport commitment. The instruction behavior has a positive influence on the intention for physical activity adherence. The learning attitude has a positive influence on sport commitment. The learning attitude has a positive influence on students' intention for physical activity adherence. The sport commitment has a positive influence on intention for physical activity adherence. It can be implied that China, as the host country of the Winter Olympics, should realize the importance of the instruction behavior of the ski classes. It can also be implied that the advanced experiences should be learned to positively guide the development of ski classes in China, and finally further expand the popularity of winter sports activities among ordinary people.
\end{abstract}

Keywords: Skiing class, Instruction behavior, Learning attitude, Sport commitment, Intention for physical activity adherence

\section{Introduction}

On July 31, 2015, the 128th International Olympic Committee Session was held in Kuala Lumpur. Beijing was elected as the host city of the 2022 Winter Olympics after beating Almaty of Kazakhstan by four votes. The Chinese government has made a great contribution to the development of the International Olympics. For example, financial and policy support have been provided to promote the popularization of winter sports. In the context of various policies

Article history:

Received (December 19, 2020), Review Result (January 26, 2021), Accepted (March 10, 2021) 
that actively promote winter sports, universities in China are facing unprecedented golden opportunities to promote the development winter sports and talent training. University is an important place for popularizing ice and snow sports and training ice and snow talents [1]. Under these circumstances, offering ski courses at university will become increasing popular, and college students can become an important force to promote winter sports. All college students (not a specific major, e.g., skiing major) have access to this sport without paying extra fees and students get credits while learning to ski [2]. Also, this kind of sport provides opportunities to promote mental and physical health, improve life quality, and reduce learning pressure [3]. Therefore, it has become an important issue for university ski education teachers as to how to guide students in ski classes in a proper manner.

Instruction behavior in physical education class refers to an influential educational activity practiced by physical education teachers to students [4]. This means that teachers must make continuous efforts and conduct research on the growth and development of students. Physical education teachers should not be content with their professional skills and educated knowledge. They are supposed to be familiar with general knowledge of sports and knowledge of students' learning characteristics [5]. Students' a positive learning attitude towards compulsory course of ski an important motivational role in deciding whether to participate in regular sports activities [6]. The fun obtained through sports activities guarantees an intention for continuous participation. Positive experiences can be the basis for guiding students to participate voluntarily, that is, sports commitment [7]. Thus, sports activities can be carried out frequently without any external control. As the commitment and enthusiasm of exercise increases, the continuity of tasks and participation also increases [8].

From the researches mentioned above, in order to meet the demand for training winter sports talents and China's education reform to promote the economic and social development of the society, it is necessary to train winter sports talents in universities. If colleges and universities start to develop and implement ski courses, ski teachers should pay attention to the influence of their instruction behavior on college students' personality. However, there is insufficient research on the relationship between ski class teachers' instruction behavior and students' learning attitude, sport commitment, and intention for physical activity adherence in China. Therefore, it is necessary to conduct this research to find out whether and what influence the instruction behavior have on students' learning attitude, sport commitment, and intention for physical activity adherence. In order to achieve the purpose of provide guidance on the direction of expanding winter sports popularity and training courses in the social context of preparing the event of 2022 Winter Olympics.

\section{Research method}

\subsection{Data collection}

In order to achieve the purpose of this study, Using the method of questionnaire survey, the data of the four variables were collected and analyzed. This study was conducted on 500 college students who participated in the ski course at $\mathrm{H}$ Sport University, which opened a ski compulsory course in China. 500 questionnaires were distributed. A total of 482 questionnaires were received (96.4\%) excluding 18 invalid questionnaires that were missing in the course of the survey. The general characteristics of the respondents of the survey who participated in the ski classes at Harbin Sport University in China surveyed in this study are given in [Table 1]. 
Table 1. Demographic characteristics of the participants

\begin{tabular}{|c|c|c|c|}
\hline Characteristics & Modalities & Frequency $(\mathrm{N})$ & Percentage $(\%)$ \\
\hline \multirow{2}{*}{ Gender } & Male & 333 & 69.1 \\
\hline & Female & 149 & 30.9 \\
\hline \multirow{4}{*}{ School year } & $1^{\text {st }}$ grade & 177 & 36.7 \\
\hline & $2^{\text {nd }}$ grade & 119 & 24.7 \\
\hline & $3^{\text {rd }}$ grade & 100 & 20.7 \\
\hline & $4^{\text {th }}$ grade & 86 & 17.8 \\
\hline \multirow{2}{*}{ Ski experience } & Yes & 291 & 60.4 \\
\hline & No & 191 & 39.6 \\
\hline \multirow{6}{*}{ Major } & Winter sports & 88 & 18.3 \\
\hline & Physical education & 111 & 23.0 \\
\hline & Sports & 127 & 26.3 \\
\hline & Social sports & 69 & 14.3 \\
\hline & Traditional sports & 53 & 11.0 \\
\hline & Others & 34 & 7.1 \\
\hline \multicolumn{2}{|c|}{ Total } & 482 & 100 \\
\hline
\end{tabular}

\subsection{Measurement instruments and reliability analysis}

Questionnaires were used to measure instruction behavior, learning attitude, sport commitment, and intention for physical activity adherence. The instruction behavior was measured by the questionnaire developed by P Chelladurai and AV Carron [9]. The learning attitude questionnaire was developed by the Korean Educational Development Institute [10], the sport commitment questionnaire used in the study was developed by Scanlan's ESCM (expansion of the sport commitment model) [11], and intention for physical activity adherence was evaluated by using a questionnaire developed by Corbin \& Lindsey [12]. Based on the Exercise Adherence Questionnaire, a conceptual and statistical review was conducted between the original and the translated version from a cultural point of view. The five questionnaires were slightly modified to meet the actual conditions of this study. With the modified questionnaires, researchers conducted questionnaire surveys in person to explain the purpose, content and other things to note when answering the questionnaire by themselves.

To confirm the reliability and validity of the questionnaire, a meeting with three physical education experts was conducted. The questionnaire was thereby modified a little to meet the purpose of the study. After that, exploratory factor analysis was conducted through a preliminary survey questionnaire to test the validity of the sample. Cronbach's $\alpha$ coefficient method is used to check the internal consistency and stability of the questionnaire. Cronbach's $\alpha$ coefficients were used to confirm the reliability of the questionnaire of the four variables: instruction behavior, learning attitude, sport commitment, and intention for physical activity adherence. 
Table 2 Reliability test result of the measurement instrument

\begin{tabular}{|c|c|}
\hline Variable & Cronbach's $\alpha$ \\
\hline Instruction Behavior & .927 \\
\hline Learning Attitude & .937 \\
\hline Sport Commitment & .905 \\
\hline Intention for Physical Activity Adherence & .893 \\
\hline
\end{tabular}

\subsection{Data analysis method}

Frequency analysis for each item of the questionnaire. In order to find out the degree of correlation between the major measurement variables, a correlation analysis and regression analysis were performed to verify the influence of the university teachers' instruction behavior on students' learning attitude, sport commitment and the intention for physical activity adherence.The influence of students' learning attitude on sport commitment and the intention for physical activity adherence. The influence of sport commitment on the intention for physical activity adherence. The statistical analysis of the data was performed by using the SPSS 22.0 program, and the statistical significance level was set to $\alpha=.05$.

\section{Research results}

\subsection{The influence of instruction behavior on learning attitude}

[Table 3] shows that training instruction behavior $(\beta=.264, \mathrm{p}<.001)$, democratic behavior $(\beta=.114, \mathrm{p}<.05)$, social support behavior $(\beta=.170), \mathrm{P}<.01)$ and positive feedback behavior $(\beta=.142, \mathrm{p}<.01)$ have a significant influence on learning attitude. The $F$ value is 51.877 , the significance probability value is .000 , and the influence of the instruction behavior on the learning attitude is $30.3 \%$.

Table 3 The regression analysis result of instruction behavior's influence on learning attitude

\begin{tabular}{|c|c|c|c|c|}
\hline \multirow{2}{*}{ Factor } & \multicolumn{3}{|c|}{ Learning attitude } & \multirow{2}{*}{$\mathrm{t}(\mathrm{p})$} \\
\cline { 2 - 5 } & $\mathrm{B}$ & $\mathrm{SE}$ & $\beta$ & \\
\hline (Constant) & 1.120 & .175 & - & $6.410(* * *)$ \\
\hline Training instruction behavior & .241 & .047 & .264 & $5.109(* * *)$ \\
\hline Democratic behaviors & .125 & .053 & .114 & $2.366\left(^{*}\right)$ \\
\hline Social support behavior & .164 & .048 & .170 & $3.403(* *)$ \\
\hline Positive feedback behavior & .137 & .044 & .142 & $3.118(* *)$ \\
\hline \multicolumn{5}{|c|}{$\mathrm{R}^{2}=.303 \mathrm{~F}=51.877 \mathrm{P}=.000$} \\
\hline
\end{tabular}




\subsection{The influence of instruction behavior on sport commitment}

[Table 4] shows that training instruction behavior $(\beta=.134, \mathrm{p}<.05)$, social support behavior ( $\beta=.141, \mathrm{p}<.01)$, democratic behavior $(\beta=.149, \mathrm{P}<.01)$ and positive feedback behavior $(\beta=.139$, $\mathrm{p}<.01)$ have a significant influence on students' sport commitment. The F value is 36.416 , the significance probability is .000 , and the influence of the instruction behavior on sport commitment is $23.4 \%$.

Table 4 The regression analysis result of instruction behavior's influence on sport commitment

\begin{tabular}{|c|c|c|c|c|}
\hline \multirow{2}{*}{ Factor } & \multicolumn{3}{|c|}{ Sport Commitment } & \multirow{2}{*}{$\mathrm{t}(\mathrm{p})$} \\
\cline { 2 - 5 } & $\mathrm{B}$ & $\mathrm{SE}$ & $\beta$ & \\
\hline (Constant) & 1.958 & .136 & - & $14.375(* * *)$ \\
\hline Training instruction behavior & .091 & .037 & .134 & $2.470(*)$ \\
\hline Democratic behaviors & .123 & .041 & .149 & $2.970(* *)$ \\
\hline Social support behavior & .138 & .037 & .192 & $3.678(* * *)$ \\
\hline Positive feedback behavior & .100 & .034 & .139 & $2.908(* *)$ \\
\hline \multicolumn{2}{|c|}{$\mathrm{R}^{2}=.234 \mathrm{~F}=36.416 \mathrm{P}=.000$} & & \\
\hline
\end{tabular}

\subsection{The influence of instruction behavior on intention for physical activity adherence}

Table 5 shows that training instruction behavior $(\beta=.157, \mathrm{p}<.01)$, democratic behavior $(\beta=.121, \mathrm{p}<.05)$, social support behavior $(\beta=.237, \mathrm{p}<.001)$ and positive feedback behavior $(\beta=.189, \mathrm{p}<.001)$ are found to have a positive effect on students' intention for physical activity adherence. The $\mathrm{F}$ value is 53.370 and the probability of significance is .000 , and the influence of the instruction behavior on intention for physical activity adherence is $30.9 \%$.

Table 5 The regression analysis result of instruction behavior's influence on intention for physical activity adherence

\begin{tabular}{|c|c|c|c|c|}
\hline \multirow{2}{*}{ Factor } & \multicolumn{2}{|c|}{ intention for physical activity adherence } & \multirow{2}{*}{$\mathrm{t}(\mathrm{p})$} \\
\cline { 2 - 5 } & $\mathrm{B}$ & $\mathrm{SE}$ & $\beta$ & \\
\hline (Constant) & 1.086 & .185 & - & $5.872(* * *)$ \\
\hline Training instruction behavior & .153 & .050 & .157 & $3.058(* *)$ \\
\hline Democratic behaviors & .142 & .056 & .121 & $2.535\left(^{*}\right)$ \\
\hline Social support behavior & .243 & .051 & .237 & $4.765(* * *)$ \\
\hline
\end{tabular}


The Influence of Instruction Behavior in University Ski Class on Students' Learning Attitude, Sport Commitment, and Intention for Physical Activity Adherence in China

\begin{tabular}{|l|l|l|l|l|}
\hline Positive feedback behavior & .194 & .047 & .189 & $4.171(* * *)$ \\
\hline \multicolumn{5}{|c|}{$\mathrm{R}^{2}=.309 \mathrm{~F}=53.370 \mathrm{P}=.000$} \\
\hline
\end{tabular}

\subsection{The influence of learning attitude on sport commitment}

[Table 6] shows that interest $(\beta=.210, \mathrm{p}<.001)$, confidence $(\beta=.200, \mathrm{p}<.001)$, attention $(\beta=.159, \mathrm{p}<.01)$ and autonomy $(\beta=.177, \mathrm{p}<.001)$ have a significant. The $\mathrm{F}$ value is 72.162 , the significance probability is .000 , and the influence of learning attitude on sport commitment is $37.7 \%$.

Table 6 The regression analysis result of the influence of learning attitude on sport commitment

\begin{tabular}{|c|c|c|c|c|}
\hline \multirow{2}{*}{ Factor } & \multicolumn{3}{|c|}{ Sport commitment } & \multirow{2}{*}{$\mathrm{t}(\mathrm{p})$} \\
\cline { 2 - 5 } & $\mathrm{B}$ & $\mathrm{SE}$ & $\beta$ & $19.949(* * *)$ \\
\hline (Constant) & 1.954 & .098 &. & $4.112(* * *)$ \\
\hline Interest & .135 & .033 & .200 & $4.255(* * *)$ \\
\hline Confidence & .103 & .024 & .159 & $3.226(* *)$ \\
\hline Attention & .104 & .032 & .177 & $3.520(* * *)$ \\
\hline Autonomy & .119 & .034 & \\
\hline \multirow{2}{*}{$\mathrm{R}^{2}=.377 \mathrm{~F}=72.162 \mathrm{P}=.000$} & \\
\hline
\end{tabular}

\subsection{The influence of learning attitude on intention for physical activity adherence}

Table 7 shows that interest $(\beta=.198, \mathrm{p}<.001)$, confidence $(\beta=.294, \mathrm{p}<.001)$, attention $(\beta=.119, p<.005)$ and autonomy $(\beta=.141, p<.01)$ were found to have a significant influence on intention for physical activity adherence. The $F$ value is 75.010 , and the significance probability is .000 , and the influence of learning attitude on intention for physical activity adherence is $38.6 \%$.

Table 7 The regression analysis result of the influence of learning attitude on intention for physical activity adherence

\begin{tabular}{|c|c|c|c|c|}
\hline \multirow{2}{*}{ Factor } & \multicolumn{3}{|c|}{ intention for physical activity adherence } & \multirow{2}{*}{$\mathrm{t}(\mathrm{p})$} \\
\cline { 2 - 5 } & $\mathrm{B}$ & $\mathrm{SE}$ & $\beta$ & $10.081(* * *)$ \\
\hline (Constant) & 1.402 & .139 & - & $3.902(* * *)$ \\
\hline Interest & .182 & .047 & .198 & $6.285(* * *)$ \\
\hline Confidence & .216 & .034 & .294 & $2.429\left(^{*}\right)$ \\
\hline Attention & .112 & .046 & .119 & $2.825\left(^{* *}\right)$ \\
\hline Autonomy & .136 & .048 & .141 & \\
\hline \multicolumn{7}{|l|}{$\mathrm{R}^{2}=.386 \mathrm{~F}=75.010 \mathrm{P}=.000$} \\
\hline$p<.05, * * p<.01, * * * p<.001$
\end{tabular}




\subsection{The influence of sport commitment on intention for physical activity adherence}

[Table 8] shows that behavioral commitment $(\beta=.266, \mathrm{p}<.001)$ and cognitive commitment $(\beta=.395, \mathrm{p}<.001)$ have a positive influence on intention for physical activity adherence. The $\mathrm{F}$ value is 131.875 , and the significance probability is .000 , and the influence of sport commitment on intention for physical activity adherence is $35.5 \%$.

Table 8. The regression analysis result of the influence of sport commitment on intention for physical activity adherence

\begin{tabular}{|c|c|c|c|c|}
\hline \multirow{2}{*}{ Factor } & \multicolumn{2}{|c|}{ intention for physical activity adherence } & \multirow{2}{*}{$\mathrm{t}(\mathrm{p})$} \\
\cline { 2 - 5 } & $\mathrm{B}$ & $\mathrm{SE}$ & $\beta$ & \\
\hline (constant) & .640 & .195 & - & $3.284(* *)$ \\
\hline Behavioral commitment & .285 & .050 & .266 & $5.749(* * *)$ \\
\hline Cognitive commitment & .567 & .067 & .395 & $8.527(* * *)$ \\
\hline \multicolumn{7}{|c|}{$\mathrm{R}^{2}=.355 \mathrm{~F}=131.875 \mathrm{P}=.000$} \\
\hline
\end{tabular}

\section{Discussions}

The results of current study are summarized, as follow: First, the instruction behavior of the Chinese university ski class was found to have a positive influence on learning attitude. Second, the instruction behavior of the Chinese university ski education class was found to have a positive influence on sport commitment. Third, the instruction behavior of the Chinese university ski class was found to have a positive influence on the intention for physical activity adherence. Fourth, the learning attitude of the Chinese university ski class was found to have a positive influence on sport commitment. Fifth, the learning attitude of Chinese university ski class was found to have a positive influence on students' intention for physical activity adherence. Sixth, the sport commitment in Chinese university skiing classes was found to have a positive significant influence on intention for physical activity adherence.

In previous studies such as Park Chan-Hong, Kim Ki-Sung [13], the research results that the physical education teacher instruction behavior have a positive effect on learning attitudes. The guidance type of judo coaches had an effect on sport commitment among the research results of Shin Seong-deuk [14]. Song Kwang-seop [15] argues that leadership types of taekwondo trainer is an important factor influencing the practitioners' exercise adherence and recommendation intention. Seo Ye-won and Kim Gyeong-sook [16] found that physical education attitude has an effect on physical education commitment. The effect of learning attitudes on continuous exercise in the study of Jung Joon-young [6]. Lee Jong-min [8], there is a causal relationship between commitment and participation persistence intention, and the higher cognitive commitment and behavioral commitment, the more impact on the participation persistence intention. The results of current research, which are in the same direction with other studies mentioned above, confirm that the instruction behavior in university ski class can have a considerable impact on students' learning attitude, sport commitment, and intention for physical activity adherence in China.

\section{Conclusion}


The Influence of Instruction Behavior in University Ski Class on Students' Learning Attitude, Sport Commitment, and Intention for Physical Activity Adherence in China

The purpose of this study was to find out the influence of instruction behavior on students' learning attitude, sport commitment and intention for physical activity adherence in skiing education classes in Chinese universities. In order to achieve the purpose of this study, the regression analysis of 482 sample data was carried out using SPSS 22.0. The results of this study showed a considerable influence of instruction behavior in university ski class on students' learning attitude, sport commitment, and intention for physical activity adherence in China. It is believed that teachers' instruction behavior, learning attitude, sport commitment and intention for physical activity adherence are related, and the importance of teachers' instruction behavior to students' learning attitude, sport commitment and intention for physical activity adherence is confirmed. The results were limited to college students who offered and participated in skiing courses at $\mathrm{H}$ University in China. Therefore, it cannot be extended to all college students who do not offer skiing courses. As a suggestion, various kinds of ski classes should be developed to promote the ski education program of Chinese universities. In the future, it is necessary to set up ski classes in accordance with social demand, taking into account of various circumstances such as the cultural characteristics and local economy of the university. It can also be implied that the advanced experiences should be learned to positively guide the development of ski classes in China, and finally further expand the popularity of winter sports activities among ordinary people.

\section{Acknowledgements}

The authors gratefully thank the H Sports University teachers' and students' for providing helps and patient collaboration.

\section{References}

[1] W. Yang, "Investigation and analysis of the status quo of skiing in colleges and universities - Taking Changchun city of Jilin and as an example," Contemporary Teaching and Research Review, no.5, pp.114, (2017)

[2] H. S. Kim, "A study on the perceived ski resort service quality, customer satisfaction and choice attribute of the participants in college ski classes," Journal of the Korea Sports Association, vol.47, no.5, pp.233-244, (2008)

[3] D. H. Kim and D. H. Roh, "Motivation of the participants according to the liberal ski goal orientation, class satisfaction, impact on exercise adherence," The Korea Sports Science Association, no.21, pp.785-794, (2012)

[4] S. S. Kwon, "Study on the middle school students' satisfaction on P.E. class according to the teaching pattern," Master's thesis, Konkuk University, (2012)

[5] S. J. Ko, "The effect of physical education teacher`s guidance behavior type on learning attitude and learning immersion," Master's thesis, Woosuk University, (2017)

[6] J. Y. Jung, "The relationship between the interesting factors of university liberal arts golf classes, learning attitude, immersion in classes, and continuous exercise," Master's thesis, Konkuk University, (2015)

[7] S. I. Park and S. Y. Lee, "The concepts of enjoyment of Korean and American children from participating physical activities," Journal of the Korean Elementary School Sports Association, vol.14, no.2, pp.57-80, (2008)

[8] J. M. Lee, "The relationship of golf instructor image, trust of golf instructor, golf commitment, participation satisfaction and participation persistence intention," Doctoral dissertation, Hanshin University, (2017)

[9] P. Chelladurai and A. V. Carron, "Leadership in Canadian association for health, physical education and recreation", Ottawa, (1978)

[10] Korea, Education, and Development Institute. KEDI-WISC. Seoul: Special Education for Book Publishing, (1991) 
[11] T. K. Scanlan, P. J. Carpenter, J. P. Simons, G. W. Schmidt, and B. Keeler, "The sport commitment model: Measurement development for the youth-sport domain," Journal of Sport and Exercise Psychology, vol.15, no.1, 16-38, (1993)

[12] C. B. Corbin, and R. Lindsey, “Concepts of physical fitness,” Dubuque, LA: Wm. C. Brown Communications, (1994)

[13] C. H. Park, K. S. Kim, “Analysis of learning attitude according to physical education teacher instruction behavior," Journal of Sports Science Research Institute, pp.99-114, (2005)

[14] S. D. Shin, "Influence of sport commitment, stress and burnout on injury psychology following the guidance type of judo coaches," Doctoral dissertation, Gyeonggi University, (2009)

[15] K. S. Song, "Leadership types of taekwondo trainer and practitioners' exercise adherence and recommendation intention," Master's thesis, Kyungwon University, (2007)

[16] Y. Seo, K. Kim, "The effect the attitude of a subject has on physical education class concentration and class satisfaction," Korean Women's Sports Association, pp.79-80, (2012)

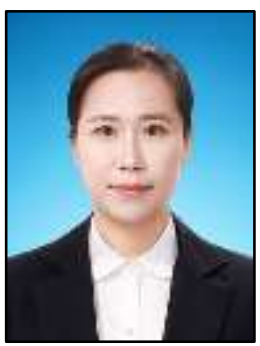

\section{TAN Rui}

$\mathrm{Ph} . \mathrm{D}$, Lecturer, Harbin Sport University, Engaged in Winter Olympic sports research level 1 certification from Canadian Association of snowboard instructor and level 2 certification from Canadian ski instructors' Alliance. She received the master of education from the Harbin Sport University, in 2012, and the degree of Doctor of science in department of physical education from the Woosuk University of Korea, in 2021. She is currently working on skiing teaching at Harbin Sport University and several the research projects of 2022 Winter Olympics.

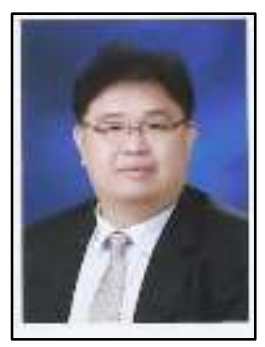

\section{Hyun Choul CHO}

Woosuk Univ. Physical Education Major. B.PE

Woosuk Univ. Physical Education Major. M.PE

Woosuk Univ. Physical Education Major. Ph.D.

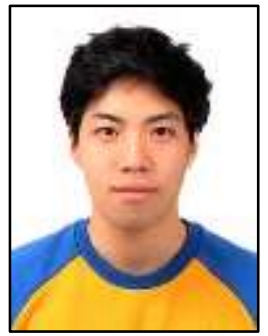

\section{JaePil SEO}

Woosuk Univ. Department of Leisure Sports. B.LS

Woosuk Univ. Physical Education Major. M.PE

Woosuk Univ. Physical Education Major. Ph.D. candidate 
The Influence of Instruction Behavior in University Ski Class on Students' Learning Attitude, Sport Commitment, and Intention for Physical Activity Adherence in China

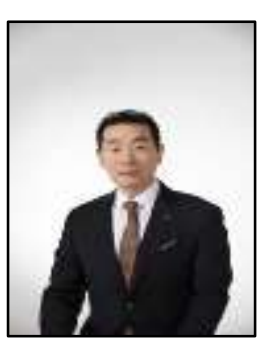

\section{Chulyung CHOI}

Ph.D, ChejuHalla Univ. professor

ChejuHalla Univ. Physical Education Major. B.PE

Chosun Univ. Physical Education Major. M.PE

Woosuk Univ. Physical Education Major. Ph.D.

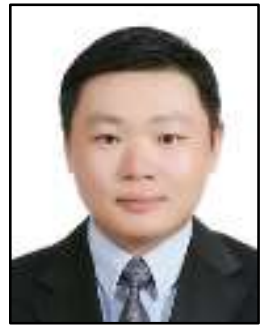

\section{YanSen LI}

Zhengzhou Univ. sports training speciality. B.Ed.

Woosuk Univ. Physical Education Major. M.PE

Woosuk Univ. Physical Education Major. Ph.D. candidate 